\title{
DANO FOLIAR EM CAFÉ ARÁBICA CAUSADO PELO BICHO MINEIRO
}

\author{
Sandy Queiroz Espinoso ${ }^{1}$ \\ Diego Souza Tosta ${ }^{2}$ \\ Richardson Sales Rocha ${ }^{3}$ \\ Louslany Almeida Oliveira ${ }^{4}$ \\ Ricardo Costa de Oliveira Júnior ${ }^{5}$ \\ Clovis Paulino ${ }^{6}$ \\ Jéferson Luiz Ferrari ${ }^{7}$
}

Resumo: O objetivo deste trabalho foi avaliar o dano foliar provocado pela ocorrência de bicho-mineiro em cafeeiros da espécie arábica, variedade Catuaí Amarelo 493. O estudo foi realizado em junho de 2016, no Instituto Federal do Espírito Santo - Campus de Alegre, ES, Brasil. Foram coletadas um par de folhas no terço superior, terço médio e terço inferior, em 25 plantas de café, escolhidas de forma aleatória. Essas amostras foram levadas até o Laboratório de Geoprocessamento e foram fotografadas, em seguida, realizadas as seguintes medições: Área total e perímetro das folhas, e área afetada pelo ataque do bichomineiro. Em média, as áreas afetadas foram de 5,8 cm (terço superior), 3,6 cm² (terço médio) e 10,6 cm² (terço inferior). O ataque pelo bicho mineiro corresponde a $23,83 \%$ no terço superior, $25,68 \%$ no terço médio e 30,68\% no inferior das plantas da lavoura.

Palavras-chave: Leucoptera coffeella; Coffea; Cutuaí; Manejo de pragas.

\footnotetext{
1 Tecnologia em Cafeicultura/Instituto Federal do Espírito Santo - Campus de Alegre, Brasil. E-mail: sandyespinoso@gmail.com.

2 Instituto Federal do Espirito Santo Campus de Alegre, Brasil. E-mail: diego.s.tosta@gmail.com.

3 Instituto Federal do Espírito Santo - Campus de Alegre, Brasil. E-mail: richardsonsales2016@gmail.com.

${ }^{4}$ Licenciatura em Ciências da Natureza/Instituto Federal Fluminense - Campus Campos Centro, Brasil. E-mail: almeidalouslany@gmail.com.

5 Instituto Federal do Espirito Santo Campus de Alegre, Brasil. E-mail: juniooliveira162@gmail.com.

6 Instituto Federal do Espirito Santo Campus de Alegre, Brasil. E-mail: clovin_mf@hotmail.com.

7 Orientador/Instituto Federal do Espírito Santo - Campus de Alegre, Brasil. E-mail: ferrarijl@ifes.edu.br.
} 